\title{
O gênero Beloesthes Thomson e nota sinonímica em Alcathousites Gilmour (Coleoptera, Cerambycidae, Lamiinae, Acanthocinini)
}

\author{
Miguel A. Monné1,2
}

\begin{abstract}
${ }^{1}$ Museu Nacional, Universidade Federal do Rio de Janeiro. Quinta da Boa Vista, 20940-040 Rio de Janeiro-RJ, Brasil. ${ }^{2}$ Pesquisador do CNPq.
\end{abstract}

\begin{abstract}
The genus Beloesthes Thomson and synonymical note on Alcathousites Gilmour (Coleoptera, Cerambycidae, Lamiinae, Acanthocinini). The genus Beloesthes Thomson, 1864 and B. megabasoides Thomson, 1864 are redescribed and figured. Alcathousites asperipennis (Fairmaire \& Germain, 1859) comb. nov (from Leiopus) = Alcathousites chaclacayoi Gilmour, 1962 syn. nov.
\end{abstract}

Keywords. Acanthocinini; Alcathousites; Beloesthes; Cerambycidae; taxonomy.

Resumo. O gênero Beloesthes Thomson, 1864 e B. megabasoides Thomson, 1864 são redescritos e figurados. Alcathousites asperipennis (Fairmaire \& Germain, 1859) comb. nov. (antes em Leiopus) = Alcathousites chaclacayoi Gilmour, 1962 syn. nov.

Palavras-Chave. Acanthocinini; Alcathousites; Beloesthes; Cerambycidae; taxonomia.

O gênero Beloesthes foi descrito por Thomson para $B$. megabasoides, sem mencionar a procedência (THOMson 1864). LACORDAire (1872), Aurivillius (1923) e BlaCKWELDER (1946) listaram-na como sendo da América do Sul. GiLmour (1965) registrou Venezuela como país de procedência sem fazer referência a exemplares examinados. Monné (1995) e Monné \& GiesberT (1995) repetiram a informação de Gilmour (l.c.). Com base em exemplares depositados na coleção do Museu Nacional, Universidade Federal dio Rio de Janeiro, Rio de Janeiro (MNRJ), o gênero e a espécie são redescritos e procedências mais precisas são fornecidas.

\section{Beloesthes Thomson, 1864}

Beloesthes Thomson, 1864: 23, 353; Lacordaire, 1872: 760; Aurivillius, 1923: 390 (cat.); Blackwelder, 1946: 611 (cat.); Gilmour, 1965: 561 (cat.); Monné, 1995: 148 (cat.); Monné \& Giesbert, 1995: 249 (cat.).

Espécie-tipo: Beloesthes megabasoides Thomson, 1864, designação original.

Olhos grosseiramente facetados; lobos superiores dos olhos tão afastados entre si quanto duas vezes a maior largura de um lobo; lobos inferiores duas vezes mais longos que a gena. Antenas alcançam os ápices dos élitros na extremidade distal do antenômero V nos machos e do antenômero VI nas fêmeas.

Protórax com tubérculo centro-lateral rombo, muito desenvolvido. Pronoto com um tubérculo obtuso e elevado a cada lado do meio; uma fileira de pontos profundos junto às margens anterior e posterior. Processo prosternal estreito, largura aproximadamente igual a um sexto de uma cavidade procoxal; processo mesosternal em declive anteriormente, com largura igual a um quarto de uma cavidade mesocoxal. Escutelo triangular, arredondado no ápice.
Élitros achatados dorso-ventralmente, sem setas eretas. Crista centro-basal elevada, com o bordo distal projetado em dente obtuso. Cada élitro com dois espinhos pós-medianos proeminentes e aguçados e um tubérculo dentiforme junto à base. Ápices com dois espinhos, o externo duas vezes mais longo que o interno.

Fêmures pedunculado-clavados; meso- e metafêmures com espinho aguçado na extremidade distal externa. Primeiro metatarsômero tão longo quanto duas vezes o comprimento dos dois seguintes reunidos.

Machos: último urotergito truncado; último urosternito semicircularmente emarginado, os ápices prolongados em forte espinho aguçado. Fêmeas: ovipositor projetado cerca de 3 $\mathrm{mm}$ além dos ápices dos élitros; último urotergito aguçado, último urosternito triangularmente entalhado.

Discussão. Beloesthes assemelha-se a Catharesthes Bates, 1881 por apresentar: élitros sem setas, com crista centro-basal e sem carenas laterais; protórax com tubérculo centro-lateral e pronoto com tubérculos; processo prosternal com menos de um quarto da largura de uma cavidade procoxal e primeiro metatarsômero com o dobro do comprimento dos dois seguintes reunidos. Difere de Catharesthes: élitros com tubérculos espiniformes pós-medianos; fêmures pedunculados e clavados; meso- e metafêmures com espinho aguçado apical externo. Em Catharesthes os élitros são desprovidos de tubérculos pós-medianos e os fêmures são inermes e fusiformes.

Beloesthes megabasoides Thomson, 1864

(Fig. 1)

Beloesthes megabasoides Thomson, 1864: 23, 253; 1878:15 (tipo); Monné, 1995: 148 (cat.); Monné \& Giesbert, 1995: 249 (cat.). 

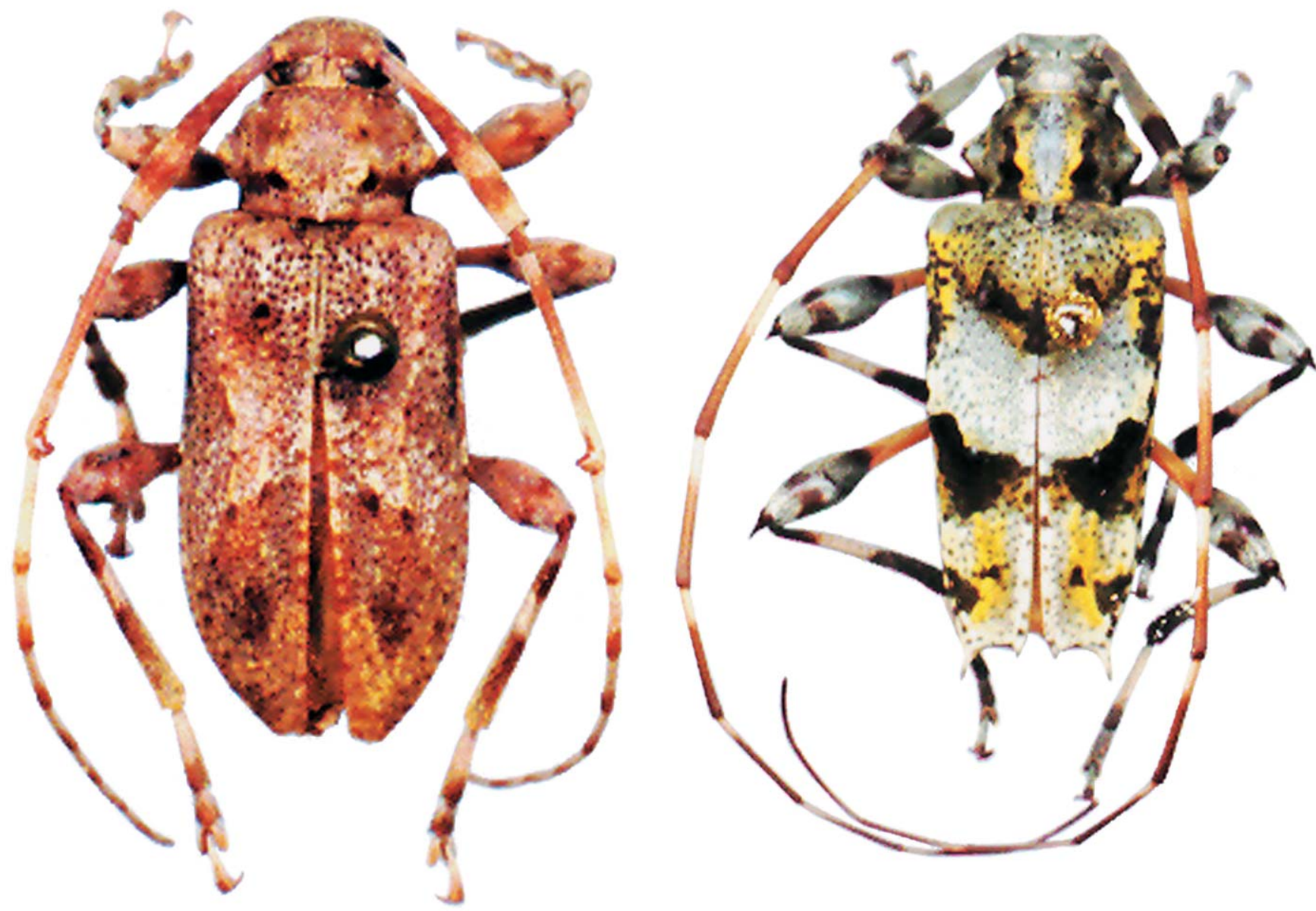

Figs. 1-2. 1, Beloesthes megabasoides Thomson, macho, Geremba, Venezuela; 2, Alcathousites asperipennis (Fairmaire \& Germain), macho, Lima, Peru.

Macho. Tegumento predominante castanho-escuro; antenômeros III-XI e base dos fêmures, castanhoavermelhados. Pubescência de maneira geral, cinza. Pubescência preta aveludada, reveste no pronoto: duas manchas na base a cada lado do meio e o lado posterior dos tubérculos; nos élitros: faixa em "V" no terço anterior, duas linhas transversais em ziguezague no terço distal, uma fileira de pequenas máculas arredondadas na declividade lateral e outra junto à sutura, no terço posterior; nas pernas: anel pósmediano nas clavas femorais, ápice distal das tíbias e os primeiros tarsômeros. Pubescência amarelo-dourada recobre os tubérculos do pronoto e pequenas máculas dispersas em toda a superfície dos élitros.

Pontuação do protórax esparsa, exceto nas fileiras junto às orlas anterior e posterior.

Superfície elitral com grânulos pilosos no terço anterior; pontuação profunda e moderadamente densa nos terços basal e distal, esparsa e pouco aparente no terço intermediário. Centro do metasterno revestido de densa pubescência amarelodourada.

Dimensões, em mm, respectivamente macho/fêmea. Comprimento total, 12,0/11,0; comprimento do protórax, 2,7/
2,4; maior largura do protórax, 3,8 /3,3; comprimento do élitro, $8,5 / 8,0 ;$ largura umeral, 4,0/4,0. As dimensões não variam de forma expressiva nos seis exemplares examinados.

Material examinado. VENEZUELA, Aragua: Geremba (2050 m), 3 machos, fêmea, 18.VI.1997, sem coletor. Distrito Federal: Caracas, macho, sem data e coletor; El Limón, fêmea, 21.VIII.1985, Bordon col. (MNRJ).

\section{Alcathousites asperipennis (Fairmaire \& Germain, 1859) comb.nov.}

(Fig. 2)

Leiopus asperipennis Fairmaire \& Germain, 1859: 513; Bosq, 1949: 80 (hosp., distr.); Monné, 1995: 152 (cat.); Monné \& Giesbert, 1995: 255 (cat.).

Alcathousites chaclacayoi Gilmour, 1962: 267, pr. 2, fig. 3; Monné, 1995: 43 (cat.); Monné \& Giesbert, 1995: 246 (cat.); Monné, 2001: 5 (hosp.). Syn. nov.

Leiopus asperipennis foi descrita do Chile, sem localidade precisa. Bose (1949), ao estudar material proveniente de Azapa, Región de Tarapaca, Provincia de Iquique, Chile, acertadamente identificou a espécie e observou: "Creemos, empero, que su permanencia en el gênero [ Leiopus] es muy 
objetable". Um exemplar do material estudado por Bosq está depositado no MNRJ, portando etiqueta com identificação deste autor como L. asperipennis. A leitura da descrição original e a confirmação da identificação do exemplar citado permitiram propor a presente sinonimia.

A larva se alimenta de Ficus sp. (Moraceae) (Bosq 1949) e Pyrus malus (Rosaceae) (WILle 1952).

Material examinado. PERU. La Libertad: Trujillo, fêmea, VI. 1939, sem coletor; macho, 22.IX.1984, L. Reys col. Lima: Lima, macho, 1958, Aurelio col.; macho, 20. I. 1962, sem coletor; Miraflores, fêmea, 12.VI.1959, Foerster col.; Rio Chillón, macho, duas fêmeas, P. Aguilar col. CHILE. Arica: Azapa, macho, fêmea, 6.XII.1948, J. M. Bosq col.(MNRJ).

\section{REFERÊNCIAS}

Aurivillius, C. 1923. Coleopterorum Catalogus, pars 74, Cerambycidae: Lamiinae. Berlin, W. Junk, p. 323-704.

Blackwelder, R. E. 1946. Checklist of the coleopterous insects of Mexico, Central America, the West Indies and South America. Part 4. Bulletin of the United States National Museum 185: 551763.

Bose, J. M. 1949. Los Cerambycidae (Insecta, Coleoptera) de Tarapacá. Agricultura Técnica 9: 77-80.

Fairmaire, L. \& P. Germain. 1859. Révision des coléoptères du Chili (suite). Annales de la Société Entomologique de France (3)7: 483-532.
Gilmour, E. F. 1962. On the Neotropical Acanthocinini (Coleoptera, Cerambycidae, Lamiinae). Some new genera and generic revision. Beiträge zur Neotropische Fauna 2(4): 249-293.

Gilmour, E. F. 1965. Catalogue des Lamiaires du Monde (Col., Cerambycidae). 8 Lief. Tutzing bei München, Museum. Georg. Frey, pp. 559-655.

Lacordaire, J. T. 1872. Histoire Naturelle des Insectes. Genera des Coléoptères, ou exposé méthodique et critique de tous les genres proposés jusqu'ici dans cet ordre d'insectes. Paris, Librairie Encyclopédique de Roret, 9(2): 411-930.

Monné, M. A. 1995. Catalogue of the Cerambycidae (Coleoptera) of the Western Hemisphere. Part XVIII. Subfamily Lamiinae: Tribe Acanthocinini. São Paulo, Sociedade Brasileira de Entomologia, $196 \mathrm{p}$.

MonnÉ, M. A. 2001. Catalogue of the Neotropical Cerambycidae (Coleoptera) with known host plant - Part III: Subfamily Lamiinae, Tribes Acanthocinini to Apomecynini. Publicações Avulsas do Museu Nacional 92: 1-94.

Monné, M. A. \& Giesbert, E. F. 1995. Checklist of the Cerambycidae and Disteniidae (Coleoptera) of the Western Hemisphere. Burbank, Wolfsgarden Books, xiv +419 p.

Thomson, J. 1864. Systema cerambycidarum ou exposé de tous les genres compris dans la famille des cérambycides et familles limitrophes. Mémoires de la Société Royal de Sciences de Liège 19: 1540 .

Thomson, J. 1878. Typi cerambycidarum Musei Thomsoniani. Paris, E. Deyrolle, $21 \mathrm{p}$.

Wille, J. E. 1952. Entomologia Agrícola del Perú. Estación Experimental de La Molina, Lima, 543 p. 